\title{
Beyond venture capital
}

\author{
John Hollway \\ You don't always have to go to venture capitalists to raise funds. Proper planning and research can help you bring in \\ millions through other avenues.
}

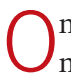
ne of the fundamental challenges in running a biotech business is the temporal alignment of two initiatives-scientific advancement and fundraising-that have no natural affinity for one another. Sometimes companies are lucky enough to raise money on the back of a scientific accomplishment, which is when it's easiest, but raising money is a constant hurdle, especially for young biotechs; there is no guarantee that the next scientific accomplishment will occur within your new financing window (or at all).

At Achaogen, we've secured commitments for more than $\$ 100$ million in alternative financing to complement the investments made by our venture capital supporters. This has not always been easy, and it has rarely been fast, but we've learned a host of lessons through our experience.

\section{Money tension}

First, some background. To date, venture capitalists (VCs) have provided a valuable supply of risk capital to the marketplace to fund high-risk, high-reward enterprises like R\&Dstage life science companies. But a potential tension exists here, as venture portfolios and companies tend to approach risk differently. VCs invest in multiple companies, technologies and therapeutic areas, and thus they can distribute their risks by putting smaller amounts of capital in play among a variety of companies. Life science companies, on the other hand, typically place a more focused bet on a single technology or therapeutic area and may seek to mitigate their risks by diversifying their funding sources or assets or conducting broader experiments to prove scientific hypotheses.

John Hollway is vice president of business development at Achaogen, South San Francisco, California, USA.

e-mail:bd@achaogen.com

\section{Box 1 The benefits of venture capital funding}

The fact that venture capital may be less easy to come by than non-dilutive financing (NDF), or that it comes at a cost of management equity in the business, certainly doesn't mean you should eschew it. Indeed, venture capitalists (VCs) bring many potential advantages to a business that NDF providers cannot bring, including access to other investors (like large pharma partners), experience in managing companies that have faced similar challenges, access to networks of new hires, validation of the management team or the underlying science, flexibility in terms and far greater speed in consummating the investment than the typical alternative funding cycle.

And certainly, money from VCs, which simply goes into a money-management account and is far more liquid than the project-based cost/reimbursement structure of most government contracts, can more rapidly be repurposed if your scientific direction changes.

The bottom line is that early investing needs to be strategic. Whether you're looking for NDF or investment from the VC community, one size definitely does not fit all. There are many options and strategies that may be valid, and knowing where the opportunities lie and deciding which to pursue and when can be the difference between having a great scientific idea and having a successful life science company.

The problem is that many risk-diversifying moves for companies can both increase the overall enterprise value of the company and reduce the short-term price of the company's shares by either raising enterprise costs or delaying advancement of a program to a value inflection point. This may create tension with the company's existing VCs, who do not like to see shares devalued.

Another potential conflict may occur when the company requires subsequent rounds of financing on the road toward an exit-a situation in which the privately held company stock can be sold and/or made publicly liquid. VCs often seek to reduce their risk by investing just enough funding to permit business operations to continue until the next scientific milestone is reached. If the milestone is reached, it should increase the value and decrease the risk of the enterprise, making it easier to raise the next round of funding. If, as not uncommonly happens, management's projections of the time and money needed to reach this milestone are inaccurate (often, though not always, due to uncontrollable external factors), the company may need additional funding before significant enterprise value has been created. Thus, life science companies and VCs are often on opposite sides of the financing table, with companies looking to raise bigger chunks of capital less frequently, which allows them to focus on science instead of fundraising while still reaching multiple milestones.

The described tensions are only heightened when the financing environment is tight. A host of issues are hurting small biotechs these days: investors' appetites for higher-risk investments have decreased; the initial public offering (IPO) market has not been terribly receptive to life science companies; big pharma is focused on programs that have achieved clinical proof of concept and can generate significant revenue in 2013 (or sooner); and VCs are more limited in their access to capital and are seeking returns in timelines that make investments in basic research unattractive. In addition to all this, the costs required for $\mathrm{R} \& \mathrm{D}$ are the same as they were before investments became scarce. 


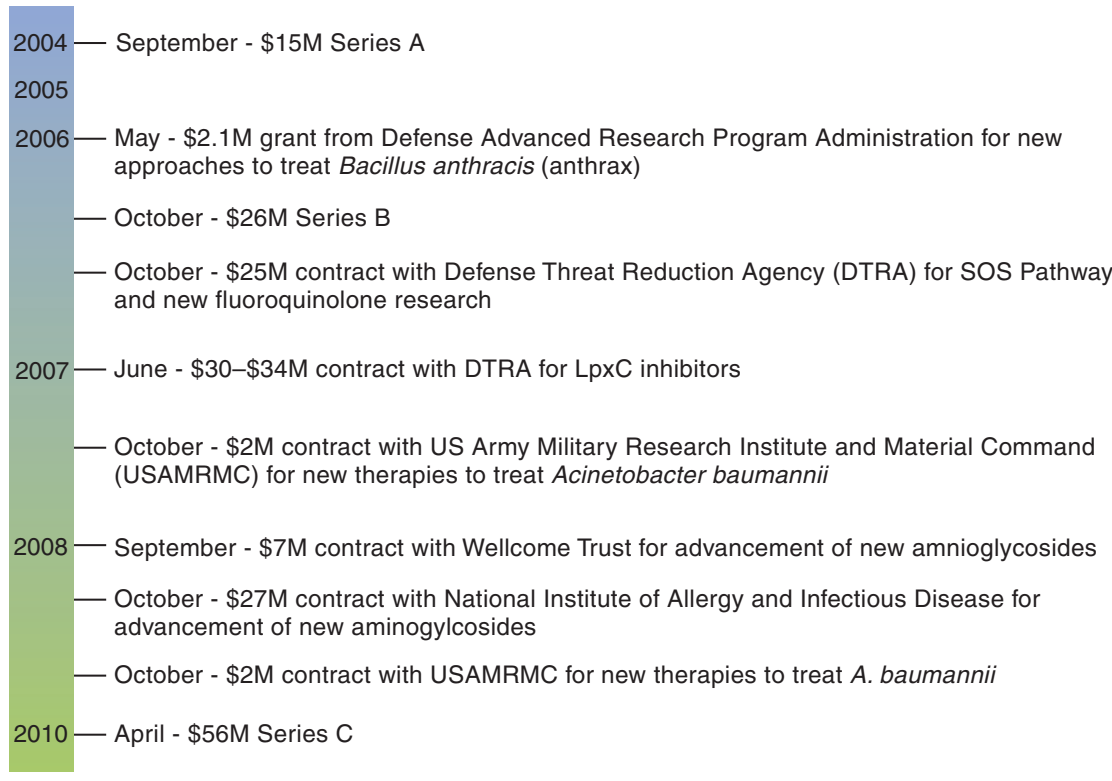

Figure 1 Achaogen's funding timeline

\section{Ways around}

Venture capital funding remains a strong option for financing your venture (Box 1), but there are other ways to help bring in money. Our company, Achaogen, which is focused on small-molecule antibacterial therapies to treat multidrug-resistant infections, has had success raising money in various ways. To date, we have raised about $\$ 100$ million in venture capital and have augmented that with over $\$ 100$ million in contractual commitments for funding from alternative sources, such as the US Department of Defense in Washington, DC; the National Institutes of Health in Bethesda, Maryland; the Wellcome Trust in London and other organizations (Fig. 1).

The company decided shortly after its founding to blend its venture capital funding with non-dilutive financing (NDF)-money from third parties that could be obtained without giving up stock. We felt we had programs the government would fund, and any time we could gain capital without relinquishing stock, we wanted to do it.

Done properly, NDF provides an external validation of the market need for your science and of the scientific rigor of your company's particular approach. It also serves to extend the company's financial runway and provides valuable capital for additional experiments. Many companies are turning to alternative sources, such as government grants or contracts, venture philanthropy organizations or hybrids of these options. These alternatives can be highly effective ways to leverage a business, but as with any financing vehicle, they present challenges and complexities over the long term that should be understood before any commitments are made. Here are nine lessons our team learned through our funding experiences.

1. 'Non-dilutive' and 'paid for' may not be the same thing. For any small company, retaining focus is crucial. Although success in any one program is unlikely, adding a second or third program in an unrelated area may actually increase the likelihood of failure in both programs due to additional costs and distractions. Alternative funding may address the cost part, but it is important to ensure that extra programs do not create distractions that undermine the company's ability to function. One example would be the funded application of a platform technology in a therapeutic area that is not a focus of the company's other development efforts (for example, if you are working in infectious disease but the National Institutes of Health wants to fund a program in inflammation research that is not commercially viable for you).

It may be that the addition of a second program in a new therapeutic area is a boon to your company, providing useful validation and diversification of your portfolio in a cashneutral way, fully funded by your partner as opposed to your stockholders. Still, there are risks for a business that goes along with adding a disparate research program, including distractions and problems with resource allocation. And, because you've entered a contract to pursue the research, you may find in the future that if you want to streamline your operations and divest the new program, the right to ter- minate may only go one way and it might not be yours. So consider things carefully before taking on a new program, even if it's coupled with sizable funding.

2. Grant financing takes time. In general, our experience is that it takes 18 months from the day you start seeking government funding to the day any money is received. For larger government contracts (greater than $\$ 3$ million), the process is started by a Broad Agency Announcement - essentially, a request for proposals for certain government initiatives. The timeline for submitting proposals is generally 4-6 months, with another 4-6 months (or more) provided for the government to review the proposals and decide on the ones that will receive tentative awards.

If yours is one of the lucky proposals to receive a tentative award, congratulations! But you are only halfway there. You then have to negotiate the contract, which can take another 4-6 months or more. Only after all of these things have happened is the contractor authorized to initiate work on the program. The challenge is the same for Small Business Innovation Research/Small Business Technology Transfer (SBIR/STTR) submissions, which are more frequent but are for smaller monetary amounts. In that arena, proposals typically receive lower priority scores on their first submission but can be resubmitted, based on the reviewing panel's comments, during the next available window for applications.

3. Proposals are themselves expensive. Proposals also take time and money to put together and require detailed budgets, specific work plans, quotes from subcontractors and the provision of abundant data, typically in a nonconfidential setting. Each proposal Achaogen has made has taken about one full-time employee (half scientific writer, half business development writer and document coordinator) 2-3 months to complete. Although giving the program that much thought has benefits, it also takes away from other tasks the employee could be doing. (However, submitting proposals does get somewhat easier after the first one, as there is quite a bit of boilerplate language desired by various government agencies.)

Also, in Achaogen's experience, the time needed to write a good grant is largely the same, regardless of the amount of money requested-so choose your proposal opportunities accordingly.

4. Always measure twice. The government, quite reasonably, requires that its contractors submit a detailed budget, complete with quotes from outsourced labor, that follows a precise 
work plan for the length of the award. The budget for this work plan will be determined in the contract negotiation phase. Typically, the agencies will not hold companies to the strict amounts laid out in the budget for each type of experiment-but they will hold the line on the total budget amount, so measure carefully.

Also, be careful of the Statement of Work portion of the proposal. Word it too vaguely and it won't be approved; word it too precisely and minor changes to the research plan over time may require repeated amendments to the contract. These will take a long time to get through the bureaucracy and can also lead to reexamination of the total budget.

5. Beware the SBIR/STTR conundrum. As of this writing, companies that have accepted money from VCs are typically ineligible for funding from SBIR/STTR sources. This is due to an overly simplistic (and probably inaccurate) interpretation of a federal rule that requires SBIR/STTR recipients to be majority-owned by US citizens. This interpretation extends the rule to limited partners of VC partnerships. The US House of Representatives recently agreed to remove this limitation, but it remains to be seen if that action will become law (Nat. Biotechnol. 27, 1065-1066, 2009).

Also, remember that these grants are typically of small size ( $\$ 200,000-\$ 1.5$ million), and multiple awards would be necessary to fund a credible drug research program from $\mathrm{R} \& \mathrm{D}$ through an investigational new drug submission. Even with the frequency of these awards, each potential grant application may be rejected, which could cause delays in your work while you scramble to find additional funding, and the amounts are such that you may run out of cash before even being able to apply for the next round.

6. Alternative funding application outcomes are binary. One of the main challenges of NDF is that although it's alluring, it's certainly not guaranteed, and funding tends to be all or nothing on a project-by-project basis. It is possible to spend months putting together a proposal and months more eagerly waitingonly to get a negative outcome that renders the entire effort useless.

The government's priorities are specific but not static, and its pockets are deep but not limitless. Also, you will not be the only company applying to receive a specific pool of money, and you may not even have a completely unique technical approach. More than 200 companies applied for the first contract that Achaogen was awarded, and only 13 companies received funding. The government will provide valuable feedback if your proposal is not accepted, so that you can begin this risky, binary process again. Make sure to set expectations with your board appropriately-every proposal has a less than $50 \%$ shot at success, and success can be incremental over several revised submissions.

7. Priorities for VCs and NDF providers differ. Typically, entities that offer alternative funding have an agenda that is noncommercial, or what is sometimes called 'super-commercial'-it has a higher purpose than simply selling drugs. One needs to be careful that terms set during NDF do not conflict with your ability to raise funds from traditional VCs.

The Institute for OneWorld Health in San Francisco, for example, focuses on medicines for the developing world, an arena in which the economics of the pharmaceutical industry have historically been challenged. This may lead to some difficult discussions and some challenging terms being placed in a funding agreement that could scare off the more commercial investors you might want to attract. (Most organizations try hard to blend a commercial return with a charitable purpose in a way that can be appealing to management, but this can be harder than it sounds. Be careful about 'hooks' in agreements like diligence requirements, ownership in developing markets or approvals over potential acquisition partners. These could scare off an acquirer or licensor down the road.)

8. A certain infrastructure is needed to support contracts. Receiving funding from the federal government can create a significant administrative burden for you. Government contractors are frequently audited, allowing the government to feel secure that business is being conducted in a way that it finds suitable. This could mean companies have to add infrastructure for time-based activity reporting, equal opportunity employment restrictions and reporting, time-limited intellectual property (IP) reporting or even the submission of quarterly (and in some instances, monthly) technical reports.

The penalties for failing to comply with this dizzying array of regulation can be severe, and the government keeps close track of contract performance, using that as a significant factor in future awards. It is important to understand this clearly before signing a government contract, so weigh the risks before applying. (Grants, which are often for smaller dollar amounts, also typically have far less burdensome compliance and communication requirements.)

9. There are implications for IP. Government contracts are relatively benign in this regard, with standard language in the Federal Acquisition Regulations allowing companies to retain ownership of patents while providing a license to the US government to use technologies invented under government-funded programs for legitimate federal purposes. Given the precision needed to manufacture most pharmaceuticals, the contracted company would remain the most likely customer of the government, but it is nonetheless important to realize what such government purposes may be, both now and in the future.

Other funding organizations (the Wellcome Trust, the Cystic Fibrosis Foundation in Bethesda, the Gates Foundation in Seattle and so on) may place different requirements on your IP as a condition of funding, including the ability to obtain the program if certain diligence obligations are not met, sell a resulting product in markets that your company is not actively pursuing and veto a merger with a partner who does not share the same philosophies of the alternative funding group.

These IP hooks can, in some cases, be sufficiently onerous to make the investment too risky for the company. Most of these enterprises, however, want you to develop the drug or else they wouldn't have agreed to fund it in the first place. Thus, there is typically some room to find a mutually acceptable middle ground.

\section{Conclusions}

VCs are not the only means of funding your company. Achaogen's strategy of combining NDF with venture capital has succeeded in taking the best from both worlds - the capital efficiency of the NDF and the broad, operational utility and excellent networks and managerial support of the VCs - to construct a company with a robust discovery and development pipeline, and we've done this without diluting our investors into oblivion. Of course, one needs investors who understand the risks of pursuing NDF aggressively, and it helps to have expertise and experience working with government officials and obtaining funding. Alternative funding organizations are out there, and they can be as valuable to you as they have been to Achaogen.
To discuss the contents of this article, join the Bioentrepreneur forum on Nature Network: http://network.nature.com/groups/bioentrepreneur/forum/topics 